\title{
Synthesis of Poly(amide-quinazolinedione)s
}

\author{
Yoshio Iwakura, Keikichi Uno, and Nguyen Chau \\ Department of Synthetic Chemistry, Faculty of Engineering, \\ The University of Tokyo, Hongo, Bunkyo-ku, Tokyo, Japan.
}

(Received May 28, 1973)

\begin{abstract}
Some aromatic bisurethanes containing amide linkage were synthesized from $p$-phenoxycarbonylaminobenzoyl chloride and aromatic diamines. Polyamides containing quinazolinedione rings in the main chain were obtained by either heating a mixture of bisurethane and aromatic bis-o-amino ester in pyridine or directly in solid state at elevated temperatures. The model reaction for the formation of quinazolinedione was carried out in pyridine. The formation of quinazolinedione ring in the polymer was investigated by infrared spectroscopy and thermal analysis. The poly(amide-quinazolinediones) were reasonably thermal stable.
\end{abstract}

KEY WORDS Bisurethanes / Aromatic Bis-o-amino Ester / Quinazolinedione / Solution Polymerization / Solid-State Polycondensation /

It has been previously reported that the respective reactivities of the isocyanate and acid chloride of aliphatic or aromatic isocyanatocarboxylic acid chlorides toward nucleophilic reagents such as amines, alcohols, and water are highly different. ${ }^{1}$ In the continued investigation of the reactions of these highly reactive compounds, the reaction of $p$-isocyanatobenzoyl chloride and phenol was undertaken. It was found that phenol reacted preferentially with the isocyanate group of this compound with addition of a small amount of di- $n$-butyltin di-laurate as catalyst to give $p$-phenoxycarbonylaminobenzoyl chloride (I). In an attempt to use this addition product to prepare ordered polymers, (I) was first reacted with aromatic diamines to prepare bisurethanes containing an amide linkage. Urethanes, especially those derived from phenol, have been used as generators for the isocyanates. In our laboratory, high molecular weight polypeptides were' synthesized from the urethanes of $\alpha$-aminoacids. ${ }^{2}$ Recently, polyureas containing a benzimidazole ring were synthesized by solidstate polycondensation from aromatic bisurethanes having a preformed benzimidazole ring and aromatic diamines. ${ }^{3}$ In the continued investigation of the polycondensation of bisurethanes, we found that quinazolinedione could be easily obtained from a urethane and an aromatic $o$-amino ester by refluxing them in a pyridine solution. By using this reaction, the polymers containing amide linkages and a quinazolinedione ring in the main chain could be produced from aromatic bisurethanes and aromatic bis-o-amino esters. In this paper, we wish to report the synthesis of poly(amide-quinazolinediones) by the pyridine solution and solid-state polycondensation.

\section{RESULTS AND DISCUSSION}

\section{Synthesis of Bisurethanes}

With addition of a small amount of di- $n$ butyltin dilaurate as catalyst, $p$-isocyanatobenzoyl chloride reacted with $1 \mathrm{~mol}$ of phenol preferentially at the isocyanate group to give $p$-phenoxy-

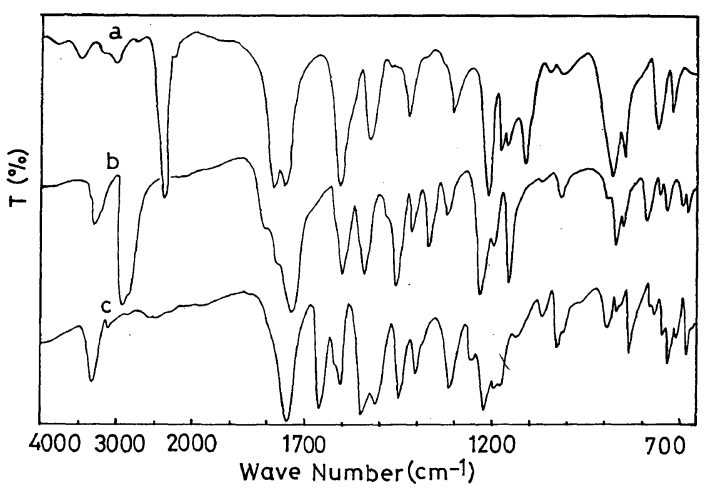

Figure 1. Infrared spectra: a, $p$-isocyanatobenzoyl chloride (without diluent); b, p-phenoxycarbonylaminobenzoyl chloride (in nujol); c, p-phenoxycarbonylaminobenzanilide ( $\mathrm{KBr}$ disk). 
carbonylaminobenzoyl chloride (I), which was characterized by the infrared spectrum and by its derivative with aniline. Figure $1 \mathrm{~b}$ indicated the absorption at $2275 \mathrm{~cm}^{-1}$ due to the isocyanate group of $p$-isocyanatobenzoyl chloride which disappeared completely when it was reacted with phenol for $24 \mathrm{hr}$. Aromatic bisurethanes containing an amide linkage were obtained by reacting (I) with aromatic diamines in aprotic organic solvents such as $N$-methylpyrrolidone and dimethylacetamide. The yields and the physical properties

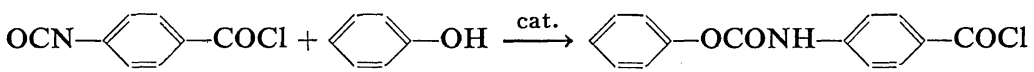

(I)

$$
\text { (I) }+\mathrm{H}_{2} \mathrm{~N}-\mathrm{R}-\mathrm{NH}_{2}
$$

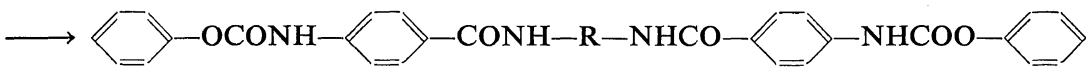

of the bisurethanes are summarized in Table I. These bisurethanes had no melting points and they dissociated into the isocyanate compounds and phenol at temperatures between $210^{\circ} \mathrm{C}$ and $330^{\circ} \mathrm{C}$ as indicated in DTA and TGA curves. Figure 2 shows an example of DTA and TGA curves of bisurethane IIA-1. The infrared spectra of bisurethane IIA-3 and the isocyanate compound obtained when heated it up to $258^{\circ} \mathrm{C}$ were shown in Figure 3. By the heat treatment, a new absorption at $2275 \mathrm{~cm}^{-1}$ due to the isocyanate group appeared along with the disappearance of the absorption of the urethane at

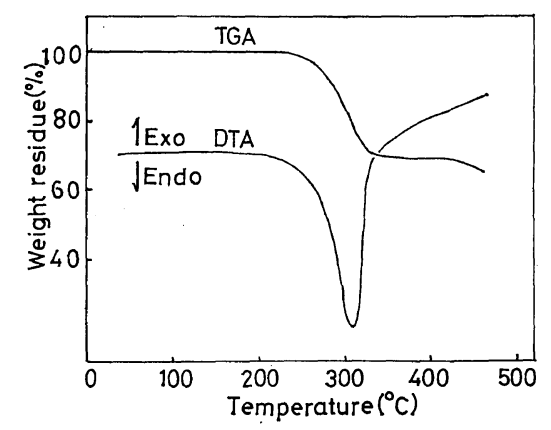

Figure 2. DTA and TGA curves of bisurethane IIA-1; heating rate, $5^{\circ} \mathrm{C} / \mathrm{min}$ in air.

Table I. Bisurethanes

\begin{tabular}{|c|c|c|c|c|c|c|}
\hline \multirow{2}{*}{ Expt no } & \multirow{2}{*}{$-\mathbf{R}-$} & \multirow{2}{*}{$\underset{\%}{\text { Yield, }}$} & \multirow{2}{*}{$\begin{array}{l}\text { Dissociating } \\
\text { temp, }{ }^{\circ}{ }^{\circ} \mathrm{C}\end{array}$} & \multicolumn{3}{|c|}{ Elemental analysis. Found (Calcd) } \\
\hline & & & & $\mathrm{C}$ & $\mathrm{H}$ & $\mathbf{N}$ \\
\hline- & & 80 & - & $\begin{array}{r}72.22 \\
(72.28\end{array}$ & $\begin{array}{l}4.94 \\
4.85\end{array}$ & $\begin{array}{l}8.61 \\
8.43)\end{array}$ \\
\hline IIA-1 & & 88 & $222-331$ & $\begin{array}{r}72.80 \\
(72.49\end{array}$ & $\begin{array}{l}4.52 \\
4.56\end{array}$ & $\begin{array}{l}8.31 \\
8.46)\end{array}$ \\
\hline IIA-2 & & 87 & $212-308$ & $\begin{array}{r}72.72 \\
(72.60\end{array}$ & $\begin{array}{l}4.72 \\
4.73\end{array}$ & $\begin{array}{l}8.12 \\
8.28)\end{array}$ \\
\hline IIA-3 & & 82 & $210-295$ & $\begin{array}{r}70.89 \\
(70.80\end{array}$ & $\begin{array}{l}4.87 \\
4.42\end{array}$ & $\begin{array}{l}8.02 \\
8.25)\end{array}$ \\
\hline IIA-4 & & 83 & $215-325$ & $\begin{array}{r}69.61 \\
(69.23\end{array}$ & $\begin{array}{l}4.47 \\
4.61\end{array}$ & $\begin{array}{l}9.55 \\
9.46)\end{array}$ \\
\hline
\end{tabular}

${ }^{\mathrm{a}}\left\langle\mathrm{Z}-\mathrm{OCONH}-\left\langle-\mathrm{CONH}-\left\langle\mathrm{mp} 218-219^{\circ} \mathrm{C}\right.\right.\right.$.

b The temperatures at which bisurethanes dissociated into isocyanates and phenol were measured by DTA and TGA (heating rate, $5^{\circ} \mathrm{C} / \mathrm{min}$, in air). 


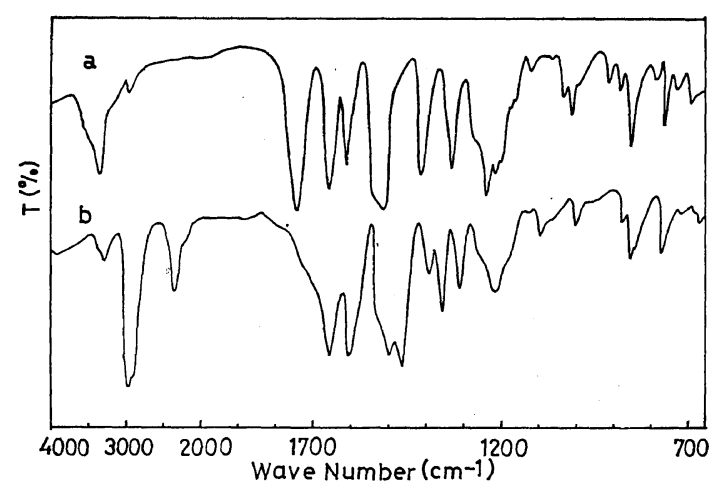

Figure 3. Infrared spectra: a, bisurethane IIA-3 $(\mathrm{KBr}$ disk); b, its isocyanate derivative obtained when heated IIA-3 up to the temperature of $258^{\circ} \mathrm{C}$ (in nujol).

$1740 \mathrm{~cm}^{-1}$, but the absorption of the amide at $1650 \mathrm{~cm}^{-1}$ showed almost no change.

Reaction of Urethane with Anthranilic Acid Methyl Ester

In order to see if quinazolinedione could be formed between urethane and aromatic $o$-amino ester, a model reaction was carried out in pyridine. Phenyl $N$-phenylcarbamate reacted with anthranilic acid methyl ester at the refluxing temperature of pyridine for $5 \mathrm{hr}$ to give 3-phenyl$2,4-(1 \mathrm{H}, 3 \mathrm{H})$-quinazolinedione (IV) in $69 \%$ yield. The reaction mechanism<smiles></smiles>

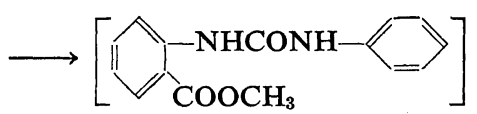

(III)<smiles>Cn1cc2[nH]c(=O)n(-c3ccccc3)c(=O)c2c1</smiles>

(IV)

was thought to be that phenyl $N$-phenylcarbamate first dissociated into phenyl isocyanate and phenol and then the isocyanate reacted with anthranilic acid methyl ester to give an urea derivative (III) followed by the ring-closing reaction to produce the compound (IV). The urea-forming reaction from urethane and amine has been demonstrated to proceed through dissociation of urethane followed by addition to the amine. ${ }^{4}$ In order to check the ring-closing reaction, the urea derivative (III) prepared from phenyl isocyanate and anthranilic acid methyl ester was used for the above reaction. As expected, (IV) was obtained from (III) in $85 \%$ yield when the reaction was carried out under a reflux of pyridine for $5 \mathrm{hr}$. This result will support the above consideration.

\section{Solution Polymerization in Pyridine}

From the result of the above reaction, the polymerization was carried out in pyridine for various aromatic bisurethanes and aromatic bis$o$-amino esters to give polymers having quinazolinedione rings in the polymer main chain as described in eq 4 .<smiles>[R]OC(=O)[14C](N)[14C]([14CH3])=O</smiles>

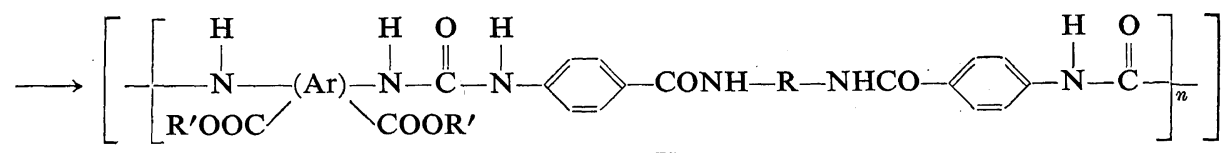<smiles>[H][Y]1N[Y10]2(C(=O)N1c1ccc(C(=O)N[R]NC=O)cc1)C(=O)N(C(C)(C)C)C(=O)[Y]2([H])C</smiles>

(VI) 
Table II. Preparation of poly(amide-quinazolindiones) from bisurethanes and bis-o-amino esters

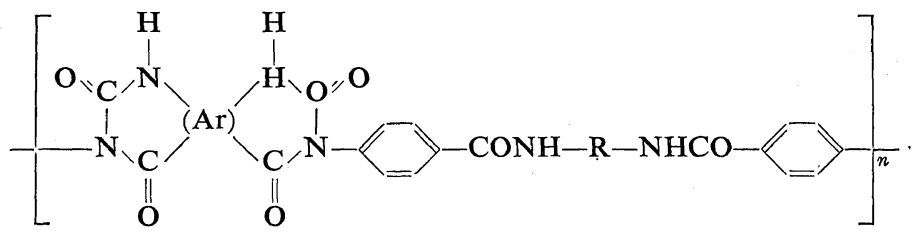

\begin{tabular}{|c|c|c|c|c|c|c|}
\hline \multirow[t]{2}{*}{ Bis-o-amino esters } & \multirow[t]{2}{*}{ Bisurethanes $-\mathbf{R}-$} & \multirow[t]{2}{*}{$\begin{array}{c}\text { Expt } \\
\text { no. }\end{array}$} & \multicolumn{2}{|c|}{$\begin{array}{l}\text { Solution } \\
\text { polymerization } \\
\text { Yield, }{ }^{\mathrm{b}} \eta_{\text {inh }^{\mathrm{a}}}\end{array}$} & \multicolumn{2}{|c|}{$\begin{array}{l}\text { Solid-state } \\
\text { polymerization } \\
\text { Yield, } \eta_{i n h}{ }^{a}\end{array}$} \\
\hline & & & $\%$ & $\mathrm{~d} l / \mathrm{g}$ & $\%$ & $\mathrm{~d} l / g$ \\
\hline \multirow{4}{*}{$\mathrm{H}_{2} \mathrm{~N} \vee \mathrm{NH}_{2}$} & & VIA-1 & $\begin{array}{l}84 \\
87 \mathrm{c}\end{array}$ & $\begin{array}{l}0.12 \\
0.11\end{array}$ & 88 & 0.19 \\
\hline & & VIA-2 & 70 & 0.12 & 85 & 0.16 \\
\hline & & VIA-3 & $\begin{array}{l}69 \\
62^{\mathrm{c}}\end{array}$ & $\begin{array}{l}0.14 \\
0.20\end{array}$ & 89 & 0.20 \\
\hline & & VIA-4 & 86 & 0.12 & 89 & 0.18 \\
\hline \multirow{4}{*}{$\mathrm{CH}_{3} \mathrm{OOC}$} & & VIA-5 & 92 & 0.10 & 88 & 0.52 \\
\hline & & VIA-6 & 65 & 0.23 & 84 & 0.39 \\
\hline & & VIA-7 & 66 & 0.19 & 86 & 0.30 \\
\hline & & VIA-8 & 85 & 0.13 & 89 & 0.56 \\
\hline$-\mathrm{COOC}_{2} \mathrm{H}_{5}$ & & VIA-9 & 97 & 0.10 & 96 & 0.21 \\
\hline \multirow[t]{3}{*}{$\mathrm{C}_{2} \mathrm{H}_{5} \mathrm{OOC} \mathrm{NH}_{2}$} & & VIA-10 & 73 & 0.23 & 89 & 0.17 \\
\hline & & VIA-11 & 80 & 0.22 & 85 & 0.20 \\
\hline & & VIA-12 & 100 & 0.14 & 100 & 0.16 \\
\hline
\end{tabular}

a Measured at a concentration of $0.5 \mathrm{~g} / 100 \mathrm{ml}$ in concentrated sulfuric acid at $30^{\circ} \mathrm{C}$.

b In pyridine, $120^{\circ} \mathrm{C}, 12 \mathrm{hr}$.

c In dimethylacetamide/pyridine, $2: 1(\mathrm{v} / \mathrm{v}), 120^{\circ} \mathrm{C}, 12 \mathrm{hr}$.

The results were listed in Table II. However, almost all of the bisurethanes used and the resultant polymers were not soluble in this solvent. The polymerization was therefore carried out in an heterogeneous state. Because of reaction condition, the molecular weight of the polymers was low as shown in Table II. An attempt to increase the molecular weight of the polymer by using a polar organic solvent such as dimethylacetamide which dissolves bisurethanes at elevated temperature did not yield polymer. The polymerization was next carried out in a mixture of pyridine and dimethylacetamide. The monomers were completely dissolved in this system. However, when the polymerization started, the polymer precipitated out of solution immediately. The viscosity of the resulted polymer, as shown in Table II, had the same value as in the case where pyridine was used as a polymerization solvent.

As described in the section on the model reaction, a quinazolinedione ring was easily formed from urethane and aromatic $o$-amino ester in pyridine; however, in the case of the polymer 


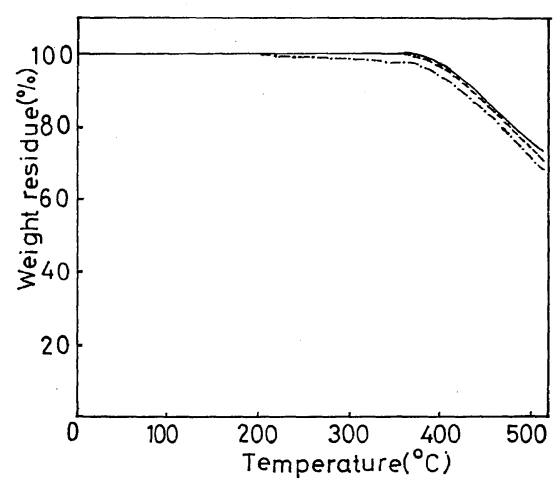

Figure 4. TGA curves: -...-, polymer VIA-1 obtained by the solution polymerization in pyridine; ----, the same polymer after heat treatment; - polymer VIA-1 obtained by the solid-state polymerization; heating rate, $5^{\circ} \mathrm{C} / \mathrm{min}$ in nitrogen atmosphere.

formation, the quinazolinedione rings in the main chain were not completely formed. The polymer obtained in pyridine gave a two-step weight loss at around $210^{\circ} \mathrm{C}$ and over $360^{\circ} \mathrm{C}$ in its TGA curve as shown in Figure 4. On the other hand, when the polymer was treated at $200-300^{\circ} \mathrm{C}$, the TGA curve of the heat treated polymer showed only a single weight loss over $360^{\circ} \mathrm{C}$.

The infrared spectra of the polymer also gave different figures before and after heat treatment. The absorption around $1700 \mathrm{~cm}^{-1}$ which corresponded to the ester group in the spectrum of the polymer obtained in pyridine disappeared completely after heat treatment (as shown in Figure 5.). The noncompletion of the ringclosing reaction in the polymer might be attributed to limitations in the polymer reaction

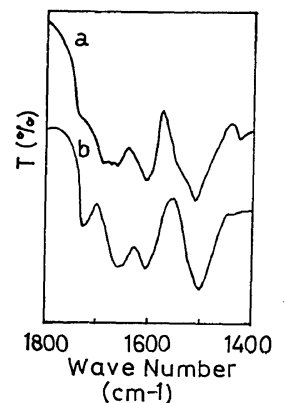

Figure 5. Infrared spectra of polymer VIA-1 obtained by the solution polymerization in pyridine: $a$, before heat treatment; $b$, after heat treatment. itself or due to the heterogeneous state of the polymerization process. To complete the formation of the quinazolinediones, the polymers resulting from the pyridine solution had to be heated in the solid state at elevated temperatures from $200^{\circ} \mathrm{C}$ to $300^{\circ} \mathrm{C}$ for $4 \mathrm{hr}$.

\section{Solid-State Polycondensation}

As described in the above section, the polyamides containing quinazolinedione rings could be produced in pyridine solution. However, in order to obtain the expected polymers, the polycondensation had to be carried out in two steps, first in pyridine and then in solid state at elevated temperatures. From this sesult, we decided to carry out the polycondensation in the solid state from the beginning. This examination was also supported by the fact that bisurethane gave the isocyanate compound when it was heated at a high temperature.

By heating a well-mixed equimolar mixture of the bisurethane and bis-o-amino ester, first at atmospheric pressure and then at reduced pressure, from 210 to $300^{\circ} \mathrm{C}$ for several hours under a nitrogen atmosphere, poly(amide-quinazolinediones) were obtained. Although one component of the reaction mixture, bis-o-amino ester melted below $215^{\circ} \mathrm{C}$ as shown in DSC curve in Figure 6, the polymerization proceeded apparently in the solid state. The results are also summarized in Table II.

In comparison with the result obtained from the solution polymerization in pyridine, the molecular weight of the polymers obtained in the solid-state process increased to some extent.

The infrared spectrum of the polymer VIA-7 was shown in Figure 7 a. The carbonyl absorption

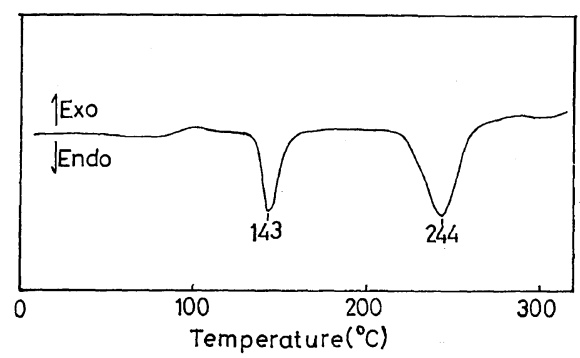

Figure 6. DSC curve of a mixture of bisurethane IIA-3 and 5,5'-methylenedianthranilic acid methyl ester; heating rate, $10^{\circ} \mathrm{C} / \mathrm{min}$ in nitrogen atmosphere. 


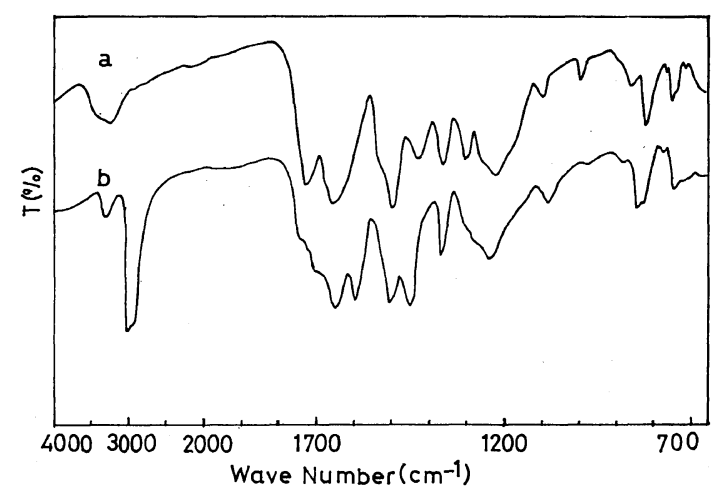

Figure 7. Infrared spectra: a, polymer VIA-7 obtained by the solid-state polymerization ( $\mathrm{KBr}$ disk); $\mathrm{b}$, product from an equimolar mixture of bisurethane IIA-3 and 5,5'-methylenedianthranilic acid methyl ester when heated them in nitrogen atmosphere at the heating rate of $10^{\circ} \mathrm{C} / \mathrm{min}$ up to the temperature of $255^{\circ} \mathrm{C}$ (in nujol).

bands appeared at 1730 and $1660 \mathrm{~cm}^{-1}$, which were assigned to the 4-carbonyl and 2-carbonyl groups of quinazolinedione, respectively. ${ }^{5}$ The absorption of the amide group seemed to overlap with that of the 2-carbonyl group of quinazolinedione to form a broad band and no ester group absorption at around $1700 \mathrm{~cm}^{-1}$ was observed. These indicated the polymer contained the amide linkages and quinazolinedione rings in the main chain.

As mentioned in the previous section, the formation of quinazolinedione was preceded by the reaction of the isocyanate dissociated from urethane and o-amino ester to form a urea intermediate in situ. By taking into consideration the fact that the reaction at solid state is slow in comparison with that in solution (because of the limited mobility of the reaction components), we attempted to check the abovementioned reaction mechanism in the solid state by stopping the polymerization process halfway to detect the expected intermediate poly(amideurea) (V). However, as shown in Figure $7 \mathrm{~b}$, the infrared spectrum of the product was that of a mixture of poly(amide-urea) and poly(amidequinazolinedione). The mechanism of the solidstate polycondensation might therefore be thought to proceed by slow dissociation of the bisurethane into the isocyanate compound and phenol followed by the rapid addition reaction of the generated isocyanate and bis-o-amino ester and the ring-closing reaction. If the addition was slower than the dissociation, an exothermic peak due to the addition reaction was expected to appear in the DSC curve. However, as shown in Figure 6, no exothermic peak was observed in DSC curve of a mixture of bisurethane and bis-o-amino ester. This observation would therefore support the above assumptive mechanism.

\section{Physical Properties of Polymers}

The resultant poly(amide-quinazolinediones) were soluble in dimethylacetamide, hexamethylphosphoramide and concentrated sulfuric acid and partially soluble in dimethylformamide, dimethylsulfoxide and $N$-methylpyrrolidone but insoluble in pyridine and $m$-cresol.

The thermogravimetric analysis showed the polymers were stable in nitrogen atmosphere up to about $360^{\circ} \mathrm{C}$ (Table III) and beyond this

Table III. Elemental analysis and thermal analysis data of poly(amide-quinazolinediones) obtained from the solid-state polycondensation

\begin{tabular}{lrllc}
\hline & \multicolumn{3}{c}{$\begin{array}{c}\text { Elemental analysis. } \\
\text { Found (Calcd) }\end{array}$} & $\begin{array}{c}\text { Initial } \\
\text { decom- } \\
\text { position }\end{array}$ \\
\cline { 2 - 5 } temp, ${ }^{\circ}{ }^{\circ} \mathrm{C}$ \\
\hline VIA-1 & \multicolumn{1}{c}{$\mathrm{C}$} & $\mathrm{H}$ & $\mathrm{N}$ & 363 \\
& $(71.08$ & 4.59 & 11.12 & 36 \\
VIA-2 & 71.81 & 3.69 & $11.83)$ & \\
& $(71.30$ & 3.83 & 11.43 & 361 \\
VIA-3 & 70.10 & 4.49 & 12.77 & 349 \\
& $(69.40$ & 3.58 & $11.56)$ & \\
VIA-4 & 68.24 & 4.50 & 12.82 & 343 \\
& $(68.14$ & 3.49 & $13.24)$ & \\
VIA-5 & 71.55 & 4.65 & 11.29 & 337 \\
& $(71.30$ & 3.87 & $11.61)$ & \\
VIA-6 & 71.71 & 4.81 & 11.33 & 355 \\
& $(71.53$ & 4.09 & $11.38)$ & \\
VIA-7 & 70.25 & 4.52 & 11.31 & 367 \\
& $(69.80$ & 3.78 & $11.35)$ & \\
VIA-8 & 69.22 & 4.16 & 12.24 & 373 \\
& $(68.50$ & 3.70 & $12.95)$ & \\
VIA-9 & 68.67 & 4.06 & 12.94 & 353 \\
& $(68.14$ & 3.49 & $13.24)$ & \\
VIA-10 & 69.49 & 4.28 & 12.25 & 357 \\
& $(68.50$ & 3.70 & $12.95)$ & \\
VIA-11 & 66.56 & 3.81 & 12.61 & 370 \\
& $(66.50$ & 3.38 & $12.92)$ & 360 \\
VIA-12 & 65.13 & 4.12 & 14.71 & \\
& $(64.51$ & 3.25 & $15.05)$ & \\
\hline
\end{tabular}

a The initial decomposition temperatures were measured by $\mathrm{TGA}$; heating rate, $5^{\circ} \mathrm{C} / \mathrm{min}$, in nitrogen atmosphere. 
Synthesis of Poly(amide-quinazolinediones)

temperature, they gradually decomposed.

\section{EXPERIMENTAL}

Pyridine was purified by distillation over potassium hydroxide.

Anthranilic acid methyl ester and diamines were commercially available.

Phenyl $N$-phenylcarbamate, $\operatorname{mp~} 127^{\circ} \mathrm{C}$ (lit., ${ }^{6}$ mp $126^{\circ} \mathrm{C}$ ) and $N$-(phenylcarbamoyl)anthranilic acid methyl ester (III), mp $144-145^{\circ} \mathrm{C}$ (lit., ${ }^{7}$ $\mathrm{mp} 144-145^{\circ} \mathrm{C}$ ) were synthesized from phenyl isocyanate and phenol and anthranilic acid methyl ester, respectively, with addition of a small amount of triethylamine as catalyst.

4,4' -Diaminobiphenyl-3, $3^{\prime}$-dicarboxylic acid methyl ester, $\mathrm{mp} 212^{\circ} \mathrm{C}$ (lit., ${ }^{8} \mathrm{mp} 213-214^{\circ} \mathrm{C}$ ) and $5,5^{\prime}$-methylenedianthranilic acid methyl ester, mp $147-148^{\circ} \mathrm{C}$ (lit., ${ }^{9} \mathrm{mp} 147^{\circ} \mathrm{C}$ ) were prepared by esterifying their corresponding acids with methanol in the presence of concentrated sulfuric acid as catalyst.

p-Diaminoterephthalic acid ethyl ester was prepared by the method of $\mathrm{H}$. Liebermann from ethyl succinate, $\mathrm{mp} 168-169^{\circ} \mathrm{C}$ (lit., ${ }^{10} \mathrm{mp} 168^{\circ} \mathrm{C}$ ).

\section{Bisurethanes}

A typical example of preparation of bisurethane IIA-3 is as follows: To a solution of $4.12 \mathrm{~g}(0.0227 \mathrm{~mol})$ of $p$-isocyanatobenzoyl chloride and $0.30 \mathrm{~g}$ of di- $n$-butyltin dilaurate in $100 \mathrm{ml}$ of ether, a solution of $2.27 \mathrm{~g}(0.0244$ $\mathrm{mol}$ ) of phenol in $30 \mathrm{ml}$ of ether was added dropwise over a period of $30 \mathrm{~min}$ at $0-5^{\circ} \mathrm{C}$ with stirring. After $24 \mathrm{hr}$ at room temperature, ether was evaporated and $80 \mathrm{ml}$ of dimethylacetamide was added to the residual solid. To this solution, $2.27 \mathrm{~g}(0.0114 \mathrm{~mol})$ of $4,4^{\prime}$-diaminobiphenylether was added at $0^{\circ} \mathrm{C}$ over a period of $5 \mathrm{~min}$. After the mixture was stirred for $2 \mathrm{hr}, 500 \mathrm{ml}$ of water was added and the precipitated solid was filtered, washed thoroughly with water and methanol and dried at $80^{\circ} \mathrm{C}$ in vacuo. The obtained bisurethane weighted $6.35 \mathrm{~g}(82 \%)$.

Model Compound, 3-Phenyl-2,4(1H,3H)-Quinazolinedione (IV)

A mixture of $3.87 \mathrm{~g}(0.0182 \mathrm{~mol})$ of phenyl $\mathrm{N}$-phenylcarbamate and $2.74 \mathrm{~g}(0.0182 \mathrm{~mol})$ of anthranilic acid methyl ester in $40 \mathrm{ml}$ of pyridine was heated at $120^{\circ} \mathrm{C}$ for $5 \mathrm{hr}$, and the reaction mixture was poured into $200 \mathrm{ml}$ of water. The solid was filtered and recrystallized from ethanol to produce colorless needles at $69-\%$ yield, $\mathrm{mp}$ $279^{\circ} \mathrm{C}$ (lit., ${ }^{7} \mathrm{mp} 280^{\circ} \mathrm{C}$ ).

Anal. Calcd for $\mathrm{C}_{14} \mathrm{H}_{10} \mathrm{~N}_{2} \mathrm{O}_{4}: \mathrm{C}, 70.58 \% ; \mathrm{H}$, $4.23 \% ; \mathrm{N}, 11.76 \%$. Found: C, 70.25\%; H, $4.33 \% ; \mathrm{N}, 11.75 \%$. By a similar procedure, (IV) was obtained in $85 \%$ yield from $N$-(phenylcarbamoyl)anthranilic acid methyl ester.

\section{POLYMERIZATION}

\section{In Pyridine Solution}

A general polymerization procedure of polymer VIA-3 is as follows: A mixture of $0.680 \mathrm{~g}(1.0 \times$ $10^{-3} \mathrm{~mol}$ ) of bisurethane IIA-3 and $0.301 \mathrm{~g}$ $\left(1.0 \times 10^{-3} \mathrm{~mol}\right)$ of $4,4^{\prime}$-diaminobiphenyl-3, $3^{\prime}$ dicarboxylic acid methyl ester in $40 \mathrm{ml}$ of pyridine was heated at $120^{\circ} \mathrm{C}$ for $12 \mathrm{hr}$. After cooling, the reaction mixture was poured into distilled water, filtered, washed with water and methanol, dried at $100^{\circ} \mathrm{C}$ in vacuo. The inherent viscosity of this polymer was $0.14\left(0.5-\% \mathrm{H}_{2} \mathrm{SO}_{4}\right.$, $30^{\circ} \mathrm{C}$ ). The polymer obtained weighed $0.579 \mathrm{~g}$.

Anal. Calcd for $\mathrm{C}_{42} \mathrm{H}_{26} \mathrm{~N}_{6} \mathrm{O}_{7}: \mathrm{C}, 69.40 \% ; \mathrm{H}$, $3.58 \%$; N, $11.56 \%$. Found: C, 69.00\%; H, $4.34 \% ; \mathrm{N}, 11.72 \%$ (after heat treatment of the polymer obtained in pyridine solution at 200$300^{\circ} \mathrm{C}$ for $4 \mathrm{hr}$ ).

\section{In Solid State}

A typical polymerization procedure for polymer VIA-7 is as follows: A mixture of $0.339 \mathrm{~g}$ $\left(0.5 \times 10^{-3} \mathrm{~mol}\right)$ of bisurethane IIA-3 and $0.157 \mathrm{~g}$ $\left(0.5 \times 10^{-3} \mathrm{~mol}\right)$ of $5,5^{\prime}$-methylenedianthranilic acid methyl ester was well mixed and charged into a one-necked flask. It was heated in a thin stream of nitrogen for $1 \mathrm{hr}$ at $220-230^{\circ} \mathrm{C}$. The flask was then evacuated to $1.0 \mathrm{mmHg}$. Heating was continued for $2 \mathrm{hr}$ at $230-240^{\circ} \mathrm{C}, 3 \mathrm{hr}$ at $250^{\circ} \mathrm{C}$ and finally $2 \mathrm{hr}$ at $250-300^{\circ} \mathrm{C}$. The obtained light yellow polymer weighed $0.317 \mathrm{~g}$ $(86 \%)$. The inherent viscosity of this polymer was $0.30\left(0.5-\% \mathrm{H}_{2} \mathrm{SO}_{4}, 30^{\circ} \mathrm{C}\right)$.

Anal. Calcd for $\mathrm{C}_{43} \mathrm{H}_{28} \mathrm{~N}_{6} \mathrm{O}_{7}: \mathrm{C}, 69.80 \% ; \mathrm{H}$, $3.78 \% ; \mathrm{N}, 11.35 \%$. Found: C, $70.25 \% ; \mathrm{H}$, $4.52 \% ; \mathrm{N}, 11.31 \%$.

\section{REFERENCES}

1. Y. Iwakura, K. Uno, and S. Kang, J. Org. Chem., 30, 1158 (1965). 
2. Y. Iwakura and Y. Ishizuka, Kobunshi Kagaku (Chem. High Polymers), 11, 540 (1954).

Y. Iwakura, Y. Ishizuka, and T. Saito, Nippon Kagaku Zasshi (J. Chem. Soc. Japan, Pure Chem. Sect.), 76, 1108 (1955).

3. Y. Iwakura, K. Uno, and K. Niiume, Preprints, SPSJ 19th Annual Meeting, Japan, Tokyo, 1, 134 (1970).

4. T. Mukaiyama and Y. Hoshino, J. Amer. Chem. Soc., 78, 1946 (1956).

5. S. Tohyama, M. Kurihara, K. Ikeda, and N.
Yoda, J. Polym. Sci. Part A-1, 5, 2523 (1967).

6. F. Gumpert, J. Prakt. Chem., 32, 281 (1885).

7. B. Taub and J. B. Hino, J. Org. Chem., 26, 5238 (1961).

8. N. Dokoshi, S. Tohyama, S. Fujita, M. Kurihara, and N. Yoda, J. Polym. Sci. Part $A-1,8,2197$ (1970).

9. H. Heller and G. Fiesselmann, Ann., 324, 130 (1902).

10. H. Liebermann, ibid., 404, 272 (1914). 